\title{
The Views of Syrian Refugees Migrating to Turkey on the Turkish Language and Culture: Kilis Case
}

\author{
Nurşat Biçer \\ Correspondence: Nurşat Biçer, M. R. Faculty of Education, Kilis 7 Aralık University, Kilis, Turkey. \\ Received: December 26, 2016 \\ Accepted: January 18, $2017 \quad$ Online Published: February 6, 2017 \\ doi:10.11114/jets.v5i3.2100 \\ URL: http://dx.doi.org/10.11114/jets.v5i3.2100
}

\begin{abstract}
This study aimed to determine the views of the Syrian refugees migrating to Kilis, Turkey on the Turkish language and culture, as well as the impact of this situation on their daily life. For that purpose, this study was done in accordance with a mixed design, using quantitative and qualitative research methods together. The target population of the quantitative study consisted of Syrian refugees between the ages of 18 and 25 who were living in Kilis. As a sample, the study was conducted with 309 participants who were chosen out of these refugees. In the qualitative part of the research, ten participants were selected out of those refugees. In the research, quantitative data were acquired through a survey prepared by the researcher, and qualitative data were obtained through face-to-face interviews and observations made in Kilis. Statistical methods and content analysis methods were employed in the data analysis. The research results have determined that Syrian refugees living in Kilis have generally positive views on the Turkish language and culture, they make an effort to learn them, and the cultural adaptation process is in progress for inclusion of the two communities.
\end{abstract}

Keywords: cultural interaction, Syria, refugees, language learning, Turkish education

\section{Introduction}

As a result of the civil war breaking out in in Syria in 2011, many Syrians were obliged to leave their country and migrated to various other countries. According to data from the UNHCR (2016) the Syrian refugee crisis is the biggest refugee crisis in the world. Countries such as Turkey, Jordan and Lebanon were severely affected by the migration wave originating from this crisis. Among these countries, Turkey was affected most by this migration movement (Yasar, 2014). In particular, the border cities of Turkey came up against an overwhelming refugee influx and significant changes occurred in the population balances of these cities. According to the figures provided by the DGMM (2016), the refugee population across Turkey was 2,744,915 in total by May 19, 2016.

Facts such as Turkey being safer, it being located at a transit hub between Asia and Europe, its proximity to their country, it having satisfactory economic conditions, and its stable government system had an impact on the movement of migration towards Turkey (Deniz, 2014; Apak, 2016; Yasar, 2014). The majority of Syrians migrating to Turkey stayed in Turkey. Turkey stopped being a country of transit and turned into a destination country.

Syrians migrating to Turkey were initially accommodated in camps, but, due to the uncontrolled increased migration wave, the refugees began to settle in places other than the camps (Oytun \& Gündoğar, 2015). Syrians living outside the camps mostly maintain their lives in the border cities where the camps are located. Syrians have spread across Turkey, including the border cities such as Kilis, Şanlıurfa, Hatay, Gaziantep, and the metropolitan areas, particularly İstanbul and Ankara, to different extents (Oytun, 2014).

Located on Syria's border, Kilis is in one of the provinces where the migration wave is intensely perceived. Resided heavily by Syrian refugees, Kilis accommodates almost as many Syrians as the members of the native population (Gökce \& Özdemirci, 2016). According to the figures provided on a by-province basis, the number of asylum seekers living inside and outside the temporary accommodation centers is 124,287 (DGMM, 2016). Changing to have province status in 1995, Kilis' population reached 130,655, which was an increase of $14.4 \%$, according to the 2015 data (TÜIK, 2016). One of the smaller cities in Turkey, Kilis borders the Syrian town of Azaz. Due to its geographical position, Kilis has hosted many refugee immigrants for the purposes of transit and settlement. Refugees settling in Kilis after these migrations were primarily accommodated in camps. According to the official figures, nearly 35,000 refugees stay in camps based around Kilis' civic center (GK, 2016). Many more Syrians are residing in Kilis civic center than are living in camps. It can be stated that Kilis, which allows so many immigrants that it has changed its own population balance, 
has experienced several problems for this reason (Oytun, 2014) As a result of its proximity to Aleppo, Kilis has become a province where Syrians have stayed with their relatives, or rented or bought houses (Paksoy, Kocarslan, Kilınc, and Tunc, 2015). Having migrated to Turkey with their families and residing there, asylum seekers can earn their keep by working as helpers for artisans from various occupational groups, as qualified employees in industry, or working in businesses operated by themselves, especially in the food sector (Cengiz, 2015). Such cases have led to a number of social, economic, and commercial results for the native population, artisans, businessmen, officers, workers, students, trainers, households, etc. (Paksoy, Kocarslan, Kılınc, and Tunc, 2015).

Upon the settlement of Syrian refugees in Turkey, an obligation arose for people with diverse cultures to keep on living together (Tunc, 2015). Syrian refugees leaving their families and their usual living conditions behind, and young Syrian refugees representing the next generation of Syria strive to create an environment in which they will be accommodated in a new social order and gain acceptance (Sezgin \& Yolcu, 2016). This harmonization process is not only to do with refugees but also with the native population living in Turkey, to a considerable extent.

Language is the basic means for an individual to express themselves in their societies, and communicate and interact with other individuals. From this perspective, it is evident that language differences lead to several problems, both for asylum seekers and the country's citizens (Akkaya, 2013). Due to the fact that Arabic is not spoken in the neighboring countries to which Syrians have migrated, it is observed that Turkey, being one of these countries, experiences more communication problems than others. Therefore, putting an emphasis on teaching Turkish to Syrians in Turkey is an important issue that will contribute to their social adaptation (Akkaya, 2013; Gün, 2015; Dönmez \& Paksoy, 2015; Tunc, 2015). Syrian adults need to learn and use Turkish to be able to find jobs and earn their own keep. Young Syrian people and children also need to learn and use it so that they will have the opportunity for education and develop their sense of belonging (Tunc, 2015). In an interview with Carol Batchelor, the UNHCR representative for Turkey, she raises the following points: "If you want to help Syrians, teach them Turkish. They must absolutely learn your language to be able to work, have education and meet their daily needs" (haberturk.com, n.d.). For that purpose, Syrian refugees have begun to learn Turkish at universities, campsites, in tent cities, and in various institutions (Gün, 2015). This situation enables Turkey and the Turkish language to grow in significance and shows the importance that should be attached to teaching Turkish as a foreign language. While activities for teaching Turkish to refugees continue, the refugees' relationships with the native population make significant contributions to language teaching.

When learning Turkish as a foreign language, Syrian refugees may initially have difficulty in learning this language, which is different from theirs. In order to minimize this difficulty, it may lead to more beneficial results to teach the Syrian refugees Turkish within the Turkish culture. The reason for this is that it is also necessary to know the cultural features of societies to be able to comprehend their value systems and perceive their frames of mind (Gün, 2015). Both learning Turkish and their cultural adaptation are important issues for Syrian refugees to be included in the native population.

The strong relationship between language and culture makes itself evident in the language learning process as well. Language and culture cannot be disassociated in the foreign language learning process (Li \& Umemoto 2010). Mert (2009) maintains that words are the linguistic marks of the concepts that a culture achieves. The nested structure of language and culture requires the planned actions to be organized in accordance with these two concepts. These facts should be emphasized, especially in the training provided for the growing generation. Taylor \& Sidhu (2012) describe that educational institutions have critical roles in the settlement of refugee children in their new country, in respect to the development of their sense of belonging and their adaptation.

Syrian refugees migrating to Turkey live together with the native population in Kilis. These populations have an effect on each other to a certain extent due to the impact of their common lives. In this environment of interaction, Syrian refugees have begun to learn the Turkish language and culture to facilitate living together with the native population, and they need to use these factors in their daily lives. It is necessary to know the refugees' perceptions of the Turkish language and culture, as well as the impact of this situation on their daily lives to enable the native population and refugees to live in harmony. Although many studies about Syrian refugees have been done so far, a study dealing with both their linguistic and cultural adaptation is required. It is quite important to conduct such a study in a province like Kilis, which is most influenced by Syrian refugees.

This study will aim to determine the perceptions of the Syrian refugees migrating to Kilis in Turkey on the Turkish language and culture, as well as the impact of this situation on daily life. Within this scope, answers to following research questions will be sought:

What are the views of the Syrian refugees living in Kilis on the Turkish language?

What are the views of the Syrian refugees living in Kilis on Turkish culture? 


\section{Method}

\subsection{Research Model}

To determine the views of Syrian refugees on Turkish language and culture, this study was prepared using a mixed method. Mixed methods require the integration of quantitative and qualitative research, and the data acquired from them (Creswell, 2007). In this sense, close examination was performed using quantitative and qualitative data together.

\subsection{Target Population and Sample}

The target population of this research was the Syrian refugees living in Kilis. The sample group of the study was composed of 309 people selected out of the target population on a voluntary basis. An appropriate sampling method was used in the sample selection. "This sampling type is associated with whether involvement of the individuals or groups to be searched in the research process is easier, or whether they are more easily accessible" (Ekiz, 2009, p.106). The participants surveyed were people living in Kilis. Table 1 shows the distribution of participants by sex, educational background, and age range:

Table 1. Distribution of participants by sex, educational background and age range

\begin{tabular}{|c|c|c|c|c|c|c|c|c|}
\hline \multirow[t]{2}{*}{ Sex } & \multicolumn{2}{|c|}{ Male } & \multicolumn{6}{|c|}{ Female } \\
\hline & 132 & $\% 42,7$ & 177 & $\% 57,3$ & & & & \\
\hline \multirow[t]{2}{*}{ Educational background } & \multicolumn{2}{|c|}{ Elementary/primary school } & \multicolumn{2}{|c|}{ Middle/junior high school } & \multicolumn{2}{|c|}{ High school } & \multicolumn{2}{|c|}{ University } \\
\hline & 4 & $\% 1,3$ & 32 & $\% 10,4$ & 167 & $\% 54,0$ & 106 & $\% 34,3$ \\
\hline \multirow[t]{2}{*}{ Age } & $18-20$ & & 21-2 & & 24-2 & & & \\
\hline & 171 & $\% 55,3$ & 42 & $\% 13,3$ & 97 & $\% 31,4$ & & \\
\hline
\end{tabular}

As can be observed from Table 1, 132 males and 177 females participated in the survey. In respect to the educational backgrounds of the participants, they were composed of 4 elementary/primary school graduates, 32 middle/junior high school graduates, 167 high school graduates and 106 university graduates. Regarding the age range of the participants, 171 were aged 18-20, 42 were aged 21-23, and 97 were aged 24-25.

In the qualitative part of the study, ten people were chosen out of these refugees, of whom four were females and six were males, and were invited to face-to-face interviews, and a close examination of the data was performed.

\subsection{Data Collection}

As this study was conducted in accordance with a mixed design, quantitative and qualitative data collection tools were used together. In the research, a survey, a semi-structured interview form and an unstructured observation form were used as data collection tools.

The process of survey development began with a literature review and a 30-item question repository was created. The items were written and a draft survey form was developed. The survey was prepared using the three-point Likert scale (i.e. yes, no, and undecided) and bilingually (Turkish and Arabic). Experts' (two Turkish teaching experts for foreigners, and one program development expert) opinions were sought to determine whether the questions represented the subject areas of the items. Necessary parts were added and it was corrected in line with the experts' opinions. Similarly, 4 out of 30 questions were omitted from the draft form because of not being considered directly associated with the research problem. The 26-item form, including the personal information form, was implemented as a pilot scheme to $10 \%$ of the application group. After the pilot scheme, two items were omitted from the survey because of decreasing the validity of the test. Cronbach's alpha coefficient was referred to regarding the reliability of the survey. Cronbach's alpha coefficient for the survey was found to be 0.72 . The widely accepted reliability coefficient value is 0.70 or more (McMillan \& Schumacher, 2010; Büyüköztürk, 2011). The 24-item survey to determine the views of Syrian refugees on Turkish language and culture was put into its final form.

The finalized survey was filled in by participants on a voluntary basis in sufficient time. Of the 350 surveys completed, the inappropriately filled in surveys were omitted and the remaining 309 surveys were used in the research.

While preparing the interview form, the expert opinions of an assistant professor working in the Turkish education field and two instructors performing Turkish teaching for foreigners were sought. The appropriate parts were corrected in line with the expert opinions. Face-to-face interviews were conducted using the finalized interview form. The students were notified and asked for their permission to audiotape the interviews. The researcher stated that they would not share the participants' names and information, and they would not use participants' names in the article after the research. The interviews recorded with an audiotape took ten minutes on average. All interviews were conducted between the researchers and participants in a setting where the participants would feel comfortable with themselves. 
While preparing the observation form, the relevant literature was reviewed and the items to be included in the observation form were specified. The created form was finalized upon seeking expert opinion on it. Unlike with the other techniques, the observation technique is based on a data creation and collection process that depends on what the researchers see, hear, and record rather than receiving direct information from someone else or referring to somebody's expressions (McMillan \& Schumacher, 2010). The observations made in Kilis' civic center were aimed at determining the impacts of language and culture on the Syrian refugees' daily lives.

\subsection{Analysis of Data}

In the analysis of the quantitative data resulting from the survey implementation in the research, the frequency and percentage distributions from descriptive statistical techniques were established through the SPSS 17 software package. This analysis tried to identify the overall predisposition of the participants towards the Turkish language and culture. In this study, the survey items were designed as a single research model without being associated with variables for the participants, and the distributions of the participants' views were determined. The views of the participants on the Turkish language and culture are presented, with the frequency and percentage distributions given in separate tables.

A content analysis method was used in the qualitative part of the study. During the interviews with the participants, the voice recording was turned into text. As part of this process, the participants were asked to make any incomprehensible expressions clear and verify them. After the process of turning the voice recording into text, the raw data were coded by the researchers. Categories were built by the specified codes. After building the codes and categories, another scorer also built codes. The formula of "Agreement / (Agreement + Disagreement) x 100" from Miles \& Huberman (1994) was utilized to ensure the reliability of data acquired through content analysis. The value of the reliability between the researchers was calculated to be 0.89 using this formula. Since an agreement percentage value of 0.70 or higher is found to be adequate (Miles \& Huberman, 1994) it can be stated that the data are reliable in terms of analysis. The codes over which there is disagreement between two scorers were discussed and finalized. Abbreviations representing the participants to specify which one of them expressed an opinion on codes were used and their frequency distributions were provided.

Data resulting from observations were presented, along with survey data. The views of participants on the Turkish language and culture were compared to the observation data. Therefore, integrated data were acquired.

\section{Results}

This chapter will present, in tables, the data collected from the surveys conducted with the Syrian refugees, from interviews and observations. Table 2 represents the views of the Syrian refugees living in Kilis on the Turkish language:

Table 2. Views on Turkish language

\begin{tabular}{|c|c|c|c|c|c|c|}
\hline & \multicolumn{2}{|l|}{ Yes } & \multicolumn{2}{|l|}{ No } & \multicolumn{2}{|c|}{ Undecided } \\
\hline & $\mathbf{N}$ & $\%$ & $\mathbf{N}$ & $\%$ & $\mathbf{N}$ & $\%$ \\
\hline $\begin{array}{l}\text { I think I will have satisfying job opportunities if I learn } \\
\text { Turkish. }\end{array}$ & 252 & 81,6 & 30 & 9,7 & 27 & 8,7 \\
\hline I can live easily in Kilis without using Turkish. & 73 & 23,6 & 192 & 62,1 & 44 & 14,2 \\
\hline I think that Turkish people should learn Arabic. & 170 & 55 & 70 & 22,7 & 69 & 22,3 \\
\hline I think Turkish is difficult to learn. & 103 & 33,3 & 157 & 50,8 & 49 & 15,9 \\
\hline $\begin{array}{l}\text { I think there are considerable differences between } \\
\text { Turkish and Arabic in terms of grammar. }\end{array}$ & 239 & 77,3 & 44 & 14,2 & 26 & 8,4 \\
\hline I can express myself in Turkish. & 190 & 61,5 & 80 & 25,9 & 39 & 12,6 \\
\hline I can understand Turkish speaking and writing. & 164 & 53,1 & 83 & 26,9 & 62 & 20,1 \\
\hline $\begin{array}{l}\text { The fact that there are Arabic-origin words in Turkish } \\
\text { makes my learning easier. }\end{array}$ & 276 & 89,3 & 16 & 5,2 & 17 & 5,5 \\
\hline I think learning Turkish has advantages. & 225 & 72,8 & 35 & 11,3 & 49 & 15,9 \\
\hline I can learn Turkish by myself. & 76 & 24,6 & 172 & 55,7 & 61 & 19,7 \\
\hline I should know Turkish to have an education. & 168 & 86,7 & 24 & 7,8 & 17 & 5,5 \\
\hline
\end{tabular}

According to the results in Table 2, the refugees in Kilis state that they place quite a strong emphasis on learning Turkish; they need to know Turkish for work and the education field; Turkish is an easy language; the fact that Arabic 
and Turkish have common words facilitates their learning; and Turkish people should also learn Arabic. Considering these points, it is understood that many people are leaning towards learning Turkish and making an effort to learn it. The reason why they want Turkish people to learn Arabic is because they wish to establish effective communication.

From the observations made in Kilis, one can conclude that refugees working with Turkish people are trying to learn Turkish; in particular, the young population knows and speaks Turkish to a certain extent, and those who know Turkish have more advantages. However, it is observed that Arabic has a strong effect in Kilis as well, and it is also used actively on signboards, bulletin boards, and in interpersonal relationships. It is evident that this situation has caused Syrians to speak Arabic more than Turkish. In addition, many Turkish people, especially the ones engaging in trade, have learned Arabic. The answers to the survey and the observations mostly support each other, and they show the general presence of the language. Table 3 illustrates the views of the Syrian refugees living in Kilis on Turkish culture:

Table 3. Views on Turkish culture

\begin{tabular}{|c|c|c|c|c|c|c|}
\hline & \multicolumn{2}{|l|}{ Yes } & \multicolumn{2}{|l|}{ No } & \multicolumn{2}{|c|}{ Undecided } \\
\hline & $\mathbf{N}$ & $\%$ & $\mathbf{N}$ & $\%$ & $\mathbf{N}$ & $\%$ \\
\hline I am able to build good relationships with Turkish people. & 218 & 70,6 & 35 & 11,3 & 56 & 18,1 \\
\hline $\begin{array}{l}\text { I do not consider Turkish people's attitudes towards me } \\
\text { disturbing. }\end{array}$ & 164 & 53,1 & 59 & 19,1 & 86 & 27,8 \\
\hline I approve of marriages to Turkish people. & 60 & 19,4 & 162 & 52,4 & 87 & 28,2 \\
\hline I do not have problems with clothes in Turkey. & 230 & 74,4 & 40 & 12,9 & 39 & 12,6 \\
\hline I think I accommodate myself to Turkey. & 200 & 64,7 & 57 & 18,4 & 52 & 16,8 \\
\hline Turkish people help me with the problems I encounter. & 107 & 34,6 & 138 & 44,7 & 64 & 20,7 \\
\hline $\begin{array}{l}\text { I see that there are similarities between Turkish culture and } \\
\text { my own culture. }\end{array}$ & 157 & 50,8 & 88 & 28,5 & 64 & 20,7 \\
\hline I like listening to Turkish songs. & 187 & 60,5 & 104 & 33,7 & 18 & 5,8 \\
\hline I have knowledge of Turkish customs and traditions. & 165 & 53,4 & 91 & 29,4 & 53 & 17,2 \\
\hline I have knowledge of Turkish national holidays. & 93 & 30,1 & 144 & 46,6 & 72 & 23,3 \\
\hline I have knowledge of Turkish society's daily lifestyles. & 187 & 60,5 & 73 & 23,6 & 49 & 15,9 \\
\hline I like watching Turkish TV series and movies. & 188 & 60,8 & 78 & 25,2 & 43 & 13,9 \\
\hline I like Turkish cuisine. & 145 & 46,9 & 119 & 38,5 & 45 & 46,9 \\
\hline
\end{tabular}

According to the results in Table 3, the refugees indicate that they have good relationships with the Turkish people in Kilis; they do not have problems with clothes; they culturally accommodate themselves to Turkey; they see that there are similarities between the Turkish culture and their own culture; they watch Turkish films and listen to Turkish songs; and they have knowledge of Turkish traditions. The statements that they do not look favorably on marriages to Turkish people and do not have knowledge of Turkish national holidays may be considered to be the only negative views on this issue. Regarding the survey items, all in all, it can be judged that refugees are disposed towards living together with Turkish people and they socialize with them.

From the observations made in Kilis, it may be concluded that there is not any disagreement between the refugees and the native population, they have several relationships with each other and they feel comfortable with their own cultural clothes, food habits and traditions. In making lives for themselves, Syrian refugees strive to accommodate themselves to Turkey by adopting several cultural features belonging to the Turkish people. Their religious beliefs, which the two nations have in common, have a significant influence on their socializing with each other. The refugees try to culturally accommodate themselves to Turkish people by maintaining their own cultural features in Kilis, where several friendship relationships have been made and at times marriages have been performed. The answers to the survey and the observations support each other, ensuring the reliability of the information. Table 4 represents the views of the Syrian refugees on using Arabic and Turkish in Kilis: 
Table 4. Use of languages in Kilis

\begin{tabular}{lll}
\hline Participant Views & & $f$ \\
\hline Using Arabic is adequate for communication. & P1, P4, P5, P7, P8, P10 & 6 \\
Knowing Turkish is necessary in daily life. & P2, P3, P6, P9 & 4
\end{tabular}

According to the results in Table 4, it is evident that Syrian refugees use Arabic intensely in their daily communication. The refugees expressed their opinions that using Arabic in Kilis is adequate for communication (f:6) and knowing Turkish is necessary in daily life (f:4). Most participants expressed that using Arabic in Kilis is adequate for communication and added that they are able to communicate easily with people without knowing Turkish. This is because there is an excessive number of Syrians in Kilis, there is a high number of Turkish people in Kilis who have learned Arabic, and there are interpreters in many places. In the survey, six participants affirm that using Arabic in Kilis is adequate for communication. The view of participant P8 is as follows:

Shopkeepers speak Arabic. Knowing Turkish is not quite necessary for daily life in Kilis because Arabic is spoken here.

In respect to this, four participants describe that knowing Turkish is necessary for daily life in Kilis. The view of participant P9, one of these participants, is as follows:

Employers prefer Syrian workers to know Turkish, but it is not a problem if they do not know Turkish. They can speak Arabic instead.

Table 5 represents the views of the Syrian refugees living in Kilis on the cases in which they need Turkish the most:

Table 5. The cases in which Turkish is needed

\begin{tabular}{lll}
\hline Participant Views & & $f$ \\
\hline Daily life & P2, P3, P4, P6, P7, P10 & 6 \\
Work & P1, P5 & 2 \\
Education & P1, P5, P9 & 3 \\
Healthcare & P1, P7 & 2
\end{tabular}

According to the results in Table 5, it is clear that Syrian refugees need to use Turkish in some cases to communicate with Turkish people. The refugees state that they need to use Turkish in fields such as daily life (f:6), business life (f:2), health care (f:2), and education (f:3). Most participants express that they need to use Turkish in daily life and declare that they cannot always find people who speak Arabic. Accordingly, six participants state that they need to use Turkish in daily life. The view of participant P6 is as follows:

I will learn a new language. I will communicate with my friends very well and speak to my neighbors well.

Here, two participants confirm that they need to use Turkish in business life and three participants state that they need it in education. The view of participant P5 is as follows:

If you are going to study at university and work with Turkish people, you should speak Turkish.

Again, two participants proclaim that they need to use Turkish in the healthcare field. The view of participant P7 is as follows:

For example, Turkish will be necessary in case of an emergency; i.e. when you feel unwell.

Table 6 includes the views of the Syrian refugees living in Kilis on the advantages of knowing Turkish for themselves:

Table 6. Advantages of knowing Turkish

\begin{tabular}{lll}
\hline Participant Views & $f$ \\
\hline Communicating with Turkish people & P1, P2, P3, P4, P6, P8, P9, P10 & 8 \\
Finding jobs & P1, P2, P3, P5, P7, P8 & 6 \\
Having education & P1, P2, P5 & 3 \\
\hline
\end{tabular}

According to the results in Table 6, it is evident that Syrian refugees believe that knowing Turkish helps them with some issues. The refugees state that they would only have opportunities such as communicating with Turkish people (f:8), finding jobs (f:6), and having an education (f:3) providing that they know Turkish. Most participants say that they communicate with Turkish people more easily when they know Turkish. Especially the young people are of the opinion that they should know Turkish to have friendships with Turkish people. The view of participant P9, who is one of eight 
participants who affirm that knowing Turkish provides an advantage for communicating with Turkish people, is as follows:

We will have stronger bonds with Turkish people if we can communicate.

Similarly, six participants describe that one advantage of knowing Turkish is that it makes it easier to find jobs and three participants state that it makes it easier to have an education. The view of participant P2 is as follows:

I can find a somewhat better job. Education will be easier for me. That is, I cannot have an education unless I learn Turkish.

Table 7 represents the views of the Syrian refugees living in Kilis on whether Turkish is an easy language or not:

Table 7. General views on Turkish

\begin{tabular}{llc}
\hline Participant Views & & $f$ \\
\hline Easy & & 9 \\
\hline Arabic and Turkish have common words & P1, P3, P4, P6, P7, P9 & 6 \\
Living in the country where Turkish is spoken & P2, P5, P10 & 3 \\
makes it easier to learn & & 3 \\
\hline Difficult & P4, P8 & 2 \\
\hline Arabic is commonly used in Kilis & P8 & 1 \\
\hline
\end{tabular}

According to the results in Table 7, Syrian refugees generally think that Turkish is an easy language. The ones who are of the opinion that Turkish is an easy language to learn state this is for reasons such as Arabic and Turkish having common words (f:6) and living in the country where Turkish is spoken makes it easier to learn (f:3). The ones who express that Turkish is a difficult language state reasons such as Arabic is commonly used in Kilis (f:2) and Turkish has a different language structure (f:1). The fact that most participants consider Turkish an easy language shows that they have positive points of view on Turkish. Likewise, six participants from the group who consider Turkish to be an easy language observe that Arabic and Turkish have common words. The view of participant P3 is as follows:

In our opinion, Turkish words are like Arabic words. This fact helps us to some extent.

Here, three participants who consider Turkish to be an easy language state that it is because they live in the country where Turkish is spoken. The view of participant P2 is as follows:

I think, Turkish is easy because we have such an opportunity. That is, we both learned and lived in this environment; therefore, we learned quickly. I learned quickly because I live in Turkey.

In respect to this point, two participants confirm that Turkish is difficult because Arabic is commonly used in Kilis and one participant states that it is because Turkish has a different language structure. The view of participant P8 is as follows:

It is difficult for Arabs because you speak in exactly the reverse order. We say the verb first and you say it last.

That is, in exactly the reverse order. Everything is easy for grammar, but bad for speaking. Because everyone speaks Arabic, I speak Arabic all day. Because we do not know Turkish, how can we speak it? If I come across a Turkish friend in the street, I do not know what to say.

Table 8 represents the views of the Syrian refugees living in Kilis on the language skill with which they have the greatest difficulty in Turkish:

Table 8. The skills with which participants have difficulty in Turkish

\begin{tabular}{llc}
\hline Participant Views & & $f$ \\
\hline Speaking & P1, P2, P5, P6, P7, P8, P9, P10 & 8 \\
Grammar & P3, P4 & 2 \\
Listening & P7 & 1
\end{tabular}

According to the results in Table 8, Syrian refugees have difficulty with some language skills in Turkish. The refugees state that they have difficulty in speaking (f:8), grammar (f:2), and listening (f:1) skills in Turkish. Most participants said that they have difficulty with speaking skills. This situation can be explained by the fact that people generally speak Arabic in Kilis, where the density of the Arab population is high. At this juncture, eight participants confirm that they 
have difficulty with speaking skills in Turkish. The view of participant P6 is as follows:

I have some difficulty in speaking, but I am increasingly improving myself.

The view of participant $\mathrm{P} 3$, who is one of two participants who state that they have difficulty with grammar in Turkish, is as follows:

Verbal adverbs in Turkish confuse us. For example, I cannot even understand what an adverb is.

The view of participant P7, who describes that they have difficulty with listening skills in Turkish, is as follows:

It is listening, because the information comes to my ear and how will I understand it? I have to both listen to and understand it. It is a bit difficult.

Table 9 represents the views of the Syrian refugees living in Kilis on which languages they watch TV channels in:

Table 9. Languages of the TV channels watched

\begin{tabular}{lll}
\hline Participant Views & & $f$ \\
\hline Arabic and Turkish & P1, P6, P9, P10 & 4 \\
Turkish channels & P2, P5 & 2 \\
English channels & P3 & 1 \\
Arabic channels & P7, P8 & 2 \\
\hline
\end{tabular}

It is evident from the results in Table 9 that Syrian refugees watch TV programs for different purposes and in different languages. The refugees assert that they watch Arabic and Turkish channels (f:4), Turkish channels (f:2), English channels (f:1), and Arabic channels (f:2). Most participants say that they watch both Turkish and Arabic channels and confirm that the older family members, in particular, watch Arabic channels in general. While these immigrants to Turkey maintain their commitment to their own language because they do not know Turkish very well, the young people, especially, are more interested in Turkish and watch Turkish TV channels. The view of participant P1, who is one of four participants who express that they watch Arabic and Turkish TV channels, is as follows:

My family watch Arabic channels. I watch only Turkish channels.

The view of participant P2, who is one of two participants who describe that they watch Turkish TV channels, is as follows:

I do not watch Arabic channels at all. This helps me with Turkish. My spouse has wanted me to watch Turkish channels since the early days when I came here because they want my Turkish to be improved.

The view of participant P3, who conveys that they watch English TV channels, is as follows:

I do not watch Turkish channels much. I watch English the most.

The view of P7, who is one of two participants who express that they watch Arabic TV channels, is as follows:

We have Arabic channels, not Turkish channels, at home. People speak Arabic at home.

Table 10 represents the views of the Syrian refugees living in Kilis on the problems they encountered in the early days when they came to Turkey:

Table 10. The problems encountered when first in Turkey

\begin{tabular}{llc}
\hline Participant Views & & $f$ \\
\hline Official procedures & P1, P5 & 2 \\
Linguistic challenges & P2, P3, P4, P5, P6, P7, P8, P10 & 8 \\
Currency diversity & P4 & 1 \\
Financial issues & P7, P9 & 2
\end{tabular}

According to the results in Table 9, it is evident that the Syrian refugees had some problems resulting from adaptation in the early days when they came to Turkey. The refugees describe that they had problems with some aspects such as official procedures (f:2), linguistic challenges (f:8), currency diversity (f:1), and financial issues (f:2) in the early days when they came to Turkey. Most participants state that they encountered linguistic challenges because they did not know Turkish when they first came to Turkey. The aforementioned problems can be regarded as cases that many refugees or immigrants coming to a new country may experience. The view of participant $\mathrm{P} 1$, who is one of two participants who had problems with official procedures in the early days when they came to Turkey, is as follows: 
I had problems in being admitted to the university. For example, Kilis admits all students, but it is very difficult at other universities. There are many Syrian students. I studied English in Syria. I submitted my admission documents to Gaziantep three times, but they did not admit me.

Here, eight participants confirm that they encountered linguistic challenges in the early days when they came to Turkey. The view of participant P8 is as follows:

Everything went badly since I did not know Turkish.

The view of participant P4, who expresses that they had problems with currency differences in the early days when they came to Turkey, is as follows:

Firstly, we had problems in understanding how much money the purchases cost. We also experienced linguistic challenges. This region is close to Syria. I did not have another problem.

In regard to this point, two participants state that they encountered economic issues in the early days when they came to Turkey. The view of participant P7 is as follows:

I had problems in finding a job because I did not know what to say, where to go and how to work. I came and worked in construction because I do not have to know the native language so much.

Table 11 represents the views of the Syrian refugees living in Kilis on the positive aspects of Turkey:

Table 11. Advantages of Turkey

\begin{tabular}{lll}
\hline Participant Views & $f$ \\
\hline A developed country & P1, P2, P3, P4, P5, P9, P10 & 7 \\
Intimate human relationships & P1, P3, P6, P7, P8 & 5 \\
Developed educational opportunities & P2, P5 & 2 \\
\hline
\end{tabular}

According to Table 11, the Syrian refugees have witnessed some positive situations while living in Turkey. The refugees affirm that they see the positive aspects of Turkey, such as the fact that it is a developed country (f:7), there are intimate human relationships (f:5), and it has developed educational opportunities (f:2). Most participants state that Turkey is a developed country. Emphasizing the interpersonal relationships among these views is also important. Participants P1, P2, P3, P4, P5, P9, and P10 express that Turkey is a developed country that has several opportunities and where people live in safety. The view of participant P3 is as follows:

Turkey is generally a beautiful and powerful country. For example, technology is getting developed. It is increasingly getting developed. It is a powerful country in every aspect.

At this juncture, five participants observe that Turkey is a country that has intimate human relationships. The view of participant P1 is as follows:

Turkish people are very kind-hearted and affectionate. Turkish people behave very well towards Syrians.

Here, two participants confirm that Turkey is a country that has developed educational opportunities. The view of participant P1 is as follows:

For example, what is important for me is the fact that there are many options concerning education in Turkey.

Table 12 represents the views of the Syrian refugees living in Kilis on the negative aspects of Turkey:

Table 12. Negative aspects of Turkey

\begin{tabular}{lll}
\hline Participant Views & & $f$ \\
\hline High cost of living & P1, P3, P4, P6 & 4 \\
Lifestyle differences & P2, P3, P9 & 3 \\
Some unfavorable behaviors of people & P3, P4, P7 & 3 \\
Official procedures & P5 & 1 \\
\hline
\end{tabular}

It is evident from the results in Table 12 that Syrian refugees have witnessed some negative situations while living in Turkey. The refugees express that Turkey has some negative aspects, such as a high cost of living (f:4), lifestyle differences (f:3), some unfavorable behaviors of people (f:3), and official procedures (f:1). Yet, two participants state that there are no negative situations that are an issue. Most participants pointed out the financial difficulties they have by referring to the high cost of living in Turkey. The view of participant P1, who is one of four participants who describe that the cost of living is high in Turkey, is as follows: 
For example, lots of things are more expensive only for Syrians. For example, a house for rent. It is cheaper in Syria. Turkish people demand money for everything. We were provided with electricity and water free of charge in Syria, but I pay for them monthly in Turkey.

The view of participant P3, who is one of three participants who state that the different lifestyle in Turkey is a negative aspect, is as follows:

I think the bazaar is closed in the early hours. It is not a good thing. For example, one may want something, but the bazaar is closed early. It is closed later in Syria.

The view of participant P7, who is one of three participants who confirm that people demonstrate some unfavorable conduct in Turkey, is as follows:

For example, I travel to another city to work, but people live at my expense; that is, they do not pay me.

The view of participant P5, who expresses that some official procedures in Turkey are negative aspects, is as follows:

I mean, the officials are challenging. In other words, the official procedures are difficult.

Table 13 represents the views of the Syrian refugees living in Kilis on the cultural differences between their country and Turkey:

Table 13. Cultural differences between Syria and Turkey

\begin{tabular}{llc}
\hline Participant Views & & $f$ \\
\hline Daily life & P4, P6, P7, P10 & 4 \\
Relationships between people & P2 & 1 \\
Traditional differences & P1, P2, P3, P5, P7, P8, P9 & 7
\end{tabular}

According to Table 13, Syrian refugees have faced some differences when they came to Turkey. The refugees observe that they have faced differences in issues such as daily life (f:4), interpersonal relationships (f:1), and traditions (f:7). Most participants express that there are a number of differences between their traditions and Turkey's traditions. It is usually the case given that each country has its own specific traditions, despite their having many common features due to being close-bordering countries. In respect to this, four participants state that there are several differences in daily life between Syria and Turkey. The view of participant P4 is as follows:

There are differences in lifestyles. For example, the shops are opened early in the morning in Turkey, but they are opened late in Syria, i.e. at 08:00 or 09:00 a.m.

The view of participant P2, who describes that there are several differences in interpersonal relationships between Syria and Turkey, is as follows:

Men sit with men and women with women in our culture, but here they sit together. Even men and women who are not so religious do not sit together.

At this juncture, seven participants confirm that there are differences in traditions between Syria and Turkey. The view of participant P5 is as follows:

Certain traditions you have in wedding ceremonies are not available in our culture. For example, you do not have some traditions we have in Ramadan.

Table 14 represents the views of the Syrian refugees living in Kilis on the cultural similarities between their country and Turkey:

Table 14. Cultural similarities between Syria and Turkey

\begin{tabular}{lll}
\hline Participant Views & & $f$ \\
\hline Similarities in religious beliefs & P1, P2, P7, P10 & 4 \\
Similarities in vocabulary & P3, P5, P6 & 3 \\
Similarities in daily life & P3, P6, P9 & 3 \\
Similarities in traditions & P4, P8 & 2
\end{tabular}

According to the results in Table 14, Syrian refugees noticed some similarities when they came to Turkey. The refugees observe some similarities such as similarities in religious beliefs (f:4), similarities in vocabulary (f:3), similarities in daily life (f:3), and similarities in traditions (f:2) between their country and Turkey. Most participants express that there are similarities in the religious beliefs between their country and Turkey. This case represents the unity in beliefs 
between the two societies. In this context, four participants state that there are similarities in religious beliefs between Syria and Turkey. The view of participant P1 is as follows:

The cultures are the same. For example, manners and customs are the same. Purdah, mosque and adhan are present in Turkey as well.

Here, three participants confirm that there are similarities in linguistic vocabulary between Syria and Turkey, and three participants again describe the lifestyle similarity. The view of participant P3 is as follows:

Some proverbs are exactly the same. I am surprised, too. That is, you use them in the same way. There are similarities in food and beverages, and clothes.

In regard to this point, two participants assert that there are similarities in traditions between Syria and Turkey. The view of participant $\mathrm{P} 4$ is as follows:

Marriages and wedding ceremonies resemble each other.

\section{Conclusion and Discussion}

This study aimed to determine the perceptions of the Syrian refugees migrating to Kilis city in Turkey on the Turkish language and culture, as well as the impact of this situation on their daily life. The survey study implemented within this scope was presented so that the observations and interview data could complement each other. As part of the survey, the Syrian refugees mainly stated that they emphasize learning Turkish and strive to learn it to find new opportunities for themselves; they also maintain that Turkish is easy to learn, especially as a result of the common words. From the observations, it is apparent that Turkish has a significant role in communicating with Turkish people, finding jobs, and getting an education. However, the fact that Arabic is widely used and has become influential is also evident. From the face-to-face interviews, it was clear that the refugees have experienced linguistic challenges in the early days when they came to Turkey; they need Turkish in daily life, Turkish is advantageous in communicating with the Turkish people, it is regarded an easy language to learn due to the common words, and many people watch Turkish TV channels. Yet, it was also expressed that using Arabic widely makes Turkish speaking a hard skill to pick up.

Considering the studies conducted in this field, such as Dönmez \& Paksoy (2015); Boyraz (2015); Gün (2011); Gün (2015); and Kirisci (2014), it is clear that Syrian refugees have experienced linguistic challenges. Conversely, Karkın \& Yazıc1 (2015) observe that the refugees migrating to Turkey do not have problems concerning the language. Dönmez \& Paksoy (2015), Arslan (2011), Gün (2015), and Kirisci (2014) stated that Syrian refugees place an emphasis on the Turkish language and make an effort to learn it. Akkaya (2013) suggests that they have positive attitudes towards Turkish. Arslan (2011) refers to the refugees' remarks that they will need Turkish in several aspects of life and Turkish will provide them with many opportunities.

The study in this paper indicates that the refugees encounter problems with speaking skills the most. Dönmez \& Paksoy (2015) also report that the refugees have the greatest difficulty with speaking skills, and that they also experience trouble with writing skills. Sezgin \& Yolcu (2016), on the other hand, ascertain that the refugees in Osmaniye who have a high school education do not have problems with speaking skills, but they experience problems with reading skills instead.

Just like the results of the study in this paper, Dönmez \& Paksoy (2015) also determine that Turkish is considered an easy language to learn because Turkish and Arabic have common words. According to Arslan (2011), the refugees state that they listen to Turkish songs and watch Turkish TV channels. From reviewing this data, it can be concluded that Turkish is considered an important language and many people want to learn it. The obstacles in the path of the two nations' socializing with each other, resulting from the linguistic diversity, will be minimized through the positive viewpoints of the people.

The survey revealed that the Syrian refugees have established close relationships with Turkish people in Kilis, and they have culturally accommodated themselves to Turkey. Consequently, it was indicated that the refugees have good relationships with the Turkish people in Kilis, they have culturally accommodated themselves to Turkey, they see that there are similarities between the Turkish culture and their own culture, they watch Turkish films and listen to Turkish songs, and they have knowledge of Turkish traditions. These observations showed that, in migrating to a new country, the Syrian refugees have striven to accommodate themselves to Turkey by adopting several cultural features belonging to the Turkish people. In Kilis, the refugees have striven to culturally accommodate themselves to Turkish people by maintaining the features of their own culture. The face-to-face interviews with these refugees have suggested that living in a country where development opportunities and intimate human relationships exist are favorable aspects, and the religious beliefs, daily lives and traditions generally resemble each other, although there are slight differences in them; however, the lifestyles are different, and people have experienced some unfavorable behaviors towards them. From these interviews, it is apparent that the Syrians generally have positive approaches to the Turkish culture and have 
adopted several cultural elements. For instance, it is possible to say that the refugees are influenced by the Turkish people in terms of several issues, such as style of dress, food habits, and behavior. It cannot be denied that the unity of religious beliefs particularly plays an important role in two nations' socializing with each other and their accommodation of each other. Karkın \& Yazıc1 (2015) and Apak (2015) describe that the refugees do not face any problems as a result of having common religious beliefs. Karkın \& Yazıcı (2015) also express that these refugees have some trouble with living according to their own cultures. Yıldız (2013) ascertains that the refugees often consider Turkish people to be close friends. Sezgin \& Yolcu (2016) determine that there are no cultural differences between Syria and Turkey, adding that the Syrian refugees and the Turkish people have good relationships with each other, in general. From Gün's (2015) perspective, the refugees experience cultural disharmony in the early days when they come to Turkey, The Syrians have accommodated themselves to Turkey to a great extent. According to Yasar (2014), the refugees have striven to accommodate themselves to Turkey by making changes in many areas, from dressing style to domestic life, and from traffic to shopping habits. As reported by Cengiz (2015), the Syrian refugees are influenced by the Turkish people in some respects, while they are keeping their own cultures alive. The presence of asylum seekers and the relationships they have established with townspeople have contributed to cultural interaction, as well as to the fact that a great deal of the population has learned Arabic and the asylum seekers have learned Turkish. The relevant studies reveal that marriages have also played a significant role in the Syrians' and Turkish people's socializing with each other (Yasar, 2014; Oytun \& Gündoğar, 2015). In this context, it can be deduced that Syrian refugees have become an important part of the social life in Turkey by several means, and have tried to accommodate themselves to Turkey through various cultural interactions.

The research has concluded that Syrian refugees place a great importance on Turkish and engage in learning this language. Turkish is significant to their communicating with the native population and these two nations experienced a cultural harmonization process to socialize with each other. Although they encountered some problems within this process, the refugees having positive points of view towards the Turkish people and Turkish culture is quite important. Within this scope, the following is recommended:

$\checkmark \quad$ The number of Turkish teaching courses should be increased to improve the Syrian refugees' communication with the native Turkish people.

$\checkmark$ Through the prospective projects, it can be ensured that Syrians will participate more actively in the social process.

$\checkmark$ Including Syrians in various service areas, such as education and healthcare, will speed up the process.

$\checkmark$ Several projects should be developed to address the cultural differences and not to hinder social harmony.

$\checkmark$ Actions to allow both nations to get to know each other better should be taken.

\section{References}

Akkaya, A. (2013). Syrian refugees' perception of the Turkish language. Ekev Academy Journal, 17(56), 179-190.

Apak, H. (2015). Future expectations of Syrian migrants: The sample of Mardin. Individual and Society Journal of Social Science, 5(9), 125-142. https://doi.org/10.20493/bt.53521

Arslan, A. (2011). A new group about teaching Turkish to foreigners: refugees and refugee students. Educational Research and Review, 6(21), 1011-1017. http://dx.doi.org/10.5897/ERR11.165.

Batchelor, C. (2016). 2 opposing views on the future of Syrian refugees in Turkey. http://www.haberturk.com/yasam/haber/1014338-turkiyedeki-suriyeli-siginmacilarin-gelecegi-ile-ilgili-2-zit-gorus. 04.05.2016.

Boyraz, Z. (2015). Syrian refugees in Turkey as an example of migrant problem. Journal of World of Turks, 7(2), 35-58.

Büyüköztürk, Ş. (2011). Data analysis handbook for social sciences. Ankara: Pegem Academy Publishing.

Cengiz, D. (2015). Spatial effect of forced migration and perception of local community; case of Kilis. Turkish Studies, 10(2), 101-122. https://doi.org/10.7827/TurkishStudies.7938

Creswell, J. W. (2007). Qualitative inquiry and research design, choosing among five approaches. Thousand Oaks, CA: Sage.

Deniz, T. (2014). Turkey from the perspective of international migration problem. TSA, 18(1), 175-204.

DGMM (Directorate General of Migration Management) (2016). Temporary protection. http://www.goc.gov.tr/icerik6/gecici-koruma_363_378_4713_icerik.13.05.2016

Dönmez, M. İ., \& Paksoy, S. (2015). A survey on the problems confronted by the Syrian students during their Turkish courses they take in Turkey: Kilis 7 Aralik University sample. International Journal of Languages' Education and 
Teaching UDES: 1907-1919. https://doi.org/10.18298/ijlet.366

Ekiz, D. (2009). Bilimsel Araştırma Yöntemleri. Ankara: Anı Publishing.

GK (Governorship of Kilis) (2016). Konteyner Kentler. http://www.kilis.gov.tr/ 02.05.2016.

Gökçe, A. F., \& Özdemirci, İ. (2016). Perception of democracy among Syrian refugees Kilis case. Mehmet Akif Ersoy University Journal of Social Sciences Institute, 8(14), 384-403. https://doi.org/10.20875/sb.68986

Gün, M. (2015). Opinions of instructors about reading skills of Syrian students learning Turkish. Educational Research and Reviews, 10(10), 1424-1433. https://doi.org/10.5897/ERR2015.2211

Gün, M. (2015). The views of teachers teaching Turkish to foreigners regarding the Turkish culture transfer to Syrian refugees learning Turkish tent city region in Adiyaman. Cappadocia Journal of History and Social Sciences, 5 , 119-138. https://doi.org/10.18299/cahij.61

Gün, Z. (2011). Perspectives for field studies with refugees and migrants: A preliminary study. In Asylum, International Migration and Statelessness: Theory, Observation and Policy, edited by O. Celebi, S. Özcurumez, and S. Turkey, 271-286. Ankara: UNHCR, http://www.unhcr.org/turkey/home.php?content=265.

Karkın, V., \& Yazıcı, Ö. (2015). Syrian Arab spring reflection and Turkey refuge refugees (Gaziantep sample). Education and Society in the $21^{\text {st }}$ Century, 4(12), 201-213.

Kirisci, K. (2014). Syrian refugees and Turkey's challenges: Going beyond hospitality. Washington: Brookings Institution.

Li, X., \& Umemoto, K. (2010). Toward an integrated approach to teaching Japanese language and culture: A knowledge perspective. Intercultural Communication Studies, XIX(2), 285-299.

McMillan, J. H., \& Schumacher. S. (2010). Research in education: Evidence-based inquiry. ( $7^{\text {th }}$ Edition). London: Pearson.

Mert, O. (2009). Tes tariat sine us from inscription of Otuken Uighur period. Ankara: Belen Publishing.

Miles, M. B., \& Huberman, M. A. (1994). Qualitative data analysis. London: Sage Publication.

Oytun, O. (2014). The situation of Syrian refugees in the neighboring countries: Findings, conclusions and recommendations. Ankara: ORSAM Report No: 189.

Oytun, O., \& Gündoğar, S. S. (2015). Effects of the Syrian refugees on Turkey. Ankara: ORSAM Report No: 195.

Paksoy, H. M., Kocarslan, H., Kılınc, E., \& Tunc, A. (2015). Suriyelilerin ekonomik etkisi: Kilis ili örneği. Individual and Society Journal of Social Science, 5(9), 143-173. https://doi.org/10.20493/bt.31618

Taylor, S., \& Sidhu, R. K. (2012). Supporting refugee students in schools: What constitutes inclusive education? International Journal of Inclusive Education, 16(1), 39-56. https://doi.org/10.1080/13603110903560085

Sezgin, A. A., \& Yolcu, T. (2016). Social cohesion and social acceptance process of incoming international students. Humanitas, 4(7), 417-436.

Tunc, A. Ş. (2015). Refugee behaviour and its social effects: An assessment of Syrians in Turkey. Turkish Journal of Tesam Academy, 2(2), 29-63.

TÜIK (Turkish Statistical Institute) (2016). Population of Provinces by Years. http://www.turkstat.gov.tr/UstMenu.do?metod=temelist 25.04.2016

UNHCR (United Nations High Commissioner for Refugees) (2016). http://www.unhcr.org.tr/ 03.04.2016

Ünal, S. (2014). Turkey's unexpected guests: Foreign immigrants and refugees experience in the context of 'other'. Journal of World of Turks, 6(3), 65-89.

Yasar, R. (2014). Perceptions about Syrian asylum seekers in Kilis. Kilis: Kilis 7 Aralık University Publishing.

Yıldız, Ö. (2013). Syrian refugees in the Turkey's camps: Problems, expectations, Turkey and future perception. Journal of Sociological Research, 16(1), 141-169.

\section{Copyrights}

Copyright for this article is retained by the author(s), with first publication rights granted to the journal.

This is an open-access article distributed under the terms and conditions of the Creative Commons Attribution license which permits unrestricted use, distribution, and reproduction in any medium, provided the original work is properly cited. 